\title{
Breast Cancer Screening: Knowledge, Attitude and Practice of Female Youths in Lugbe Community of Abuja Nigeria
}

\author{
Oluwatobi Joseph Adesokan ${ }^{1}$, Ebenezer Obi Daniel ${ }^{1, ~ *, ~ P a u l ~ O l a i y a ~ A b i o d u n ~}{ }^{1}$, \\ Ahmed Mamuda Bello ${ }^{1}$, Kabir Yunusa Amari ${ }^{3}$, Israel Olukayode Popoola ${ }^{2}$, \\ Christie Omolola Adams ${ }^{1}$, Olayinka Victor Ojo ${ }^{1}$, Adekola Odunlade ${ }^{4}$ \\ ${ }^{1}$ Department of Public Health, Texila American University, Georgetown, Guyana \\ ${ }^{2}$ Department of Epidemiology and Community Health, University of Ilorin, Ilorin, Nigeria \\ ${ }^{3}$ Department of Psychology, Benue State University, Makurdi, Nigeria \\ ${ }^{4}$ Department of Medical Rehabilitation, Obafemi Awolowo University, Ile-Ife, Nigeria
}

Email address:

dannypressy@yahoo.com (E. O. Daniel)

${ }^{*}$ Corresponding author

\section{To cite this article:}

Oluwatobi Joseph Adesokan, Ebenezer Obi Daniel, Paul Olaiya Abiodun, Ahmed Mamuda Bello, Kabir Yunusa Amari, Israel Olukayode Popoola, Christie Omolola Adams, Olayinka Victor Ojo, Adekola Odunlade. Breast Cancer Screening: Knowledge, Attitude and Practice of Female Youths in Lugbe Community of Abuja Nigeria. Cancer Research Journal. Vol. 9, No. 1, 2021, pp. 1-7. doi: $10.11648 /$ j.crj.20210901.11

Received: December 13, 2020; Accepted: December 21, 2020; Published: January 4, 2021

\begin{abstract}
More than one million women are diagnosed with breast cancer worldwide each year and over half of whom will die from the disease. The most common cancer and the leading cause of cancer death for women has been Breast cancer. Although, the prognosis of breast cancer has been improved via extensive breast cancer screening programmes and the development of new treatments. The goals of studies that focus on the early diagnosis and treatment of breast cancer have not yet been achieved and therefore, it is recognized that even among young people, knowledge about breast cancer is inadequate and the inadequacy of knowledge and practice make early diagnosis and effective treatment difficult. This study aimed at assessing Knowledge, Attitude and practice of young female in Lugbe community of Abuja, Nigeria. Three hundred and seventeen female youth participated in this cross-sectional descriptive study. Participants were recruited using Simple random sampling technique. A 52-item questionnaire on the self-reported knowledge, attitudes and practices towards breast cancer screening was formulated and used for data collection. A large proportion of the participants are between the age 21-25 $(49.8 \%)$. About three quarter $241(76 \%)$ of the respondents were single. This study revealed that $67.8 \%(215)$ of the respondents have good knowledge towards breast cancer screening while $32.2 \%$ (102) have poor knowledge about breast cancer screening, $80.1 \%$ (254) of the respondents have good attitudes towards breast cancer screening while 19.9\% (63) have poor attitudes towards breast cancer screening and only $12.6 \%$ (254) of the respondents have good practices towards breast cancer screening while majority $87.4 \%$ (277) have poor practices towards breast cancer screening. There is a statistically significant association between marital status, highest educational level, occupation of female youths and knowledge about breast cancer screening while highest educational level, religion, occupation have statistical association with the attitudes of female youths towards breast cancer screening and Age-group, highest educational level have statistical association with practices towards breast cancer screening. This research has shown that majority of female youth have good knowledge and attitude about breast cancer screening but has poor practice towards breast cancer screening. Therefore, schools, community, religion centres and government should design programs that will create better awareness on the importance of breast cancer screening, how it is done, when and where breast cancer screening can be accessed. It is also indispensably important that screening facilities should be provided in primary health care centres to improve availability and accessibility to this essential life-saving service among young female population.
\end{abstract}

Keywords: Cancer, Youth, Knowledge, Attitude, Practice 


\section{Introduction}

More than one million women are diagnosed with breast cancer worldwide each year and over half of whom will die from the disease [1]. The most common cancer and the leading cause of cancer death for women has been Breast cancer [2]. GLOBOCAN 2012 [3] data revile that breast cancer which is the most frequent cancer among women is the second most common cancer in the world with an estimated 1.67 million new cancer cases diagnosed in 2012 ( $25 \%$ of all cancers). Cancer prevention and early detection are central to the American Cancer Society's mission to save lives, celebrate lives, and lead the fight for a world without cancer. Cancer incidence has decreased among men over the past several years while remaining stable among women; cancer mortality has declined in recent decades [4]. Implementing evidence-based interventions to reduce cancer risk factors and increase cancer screening uptake can prevent additional cancer morbidity and mortality [5]. The prognosis of breast cancer has been improved via extensive breast cancer screening programs and the development of new treatments. Although, the average 5-year survival rate for women with late stage or advanced breast cancer remain slow. Five years after diagnosis, on average, only $35 \%$ of women with advanced breast cancer are alive [6]. one third of women are diagnosed with breast cancer at a late stage 4 when the disease has a poor prognosis. In all types of cancer, Breast cancer ranks as the second cause of death, after lung cancer, and it is the most frequent cause of cancer death in women in less developed regions. Although, it is now the second cause of cancer death in more developed regions too now [7]. Certain risk factors play an important role in breast cancer development which include; breast cancer in firstdegree relatives, late menopause, early menarche, and advanced age [8].

The goals of studies that focus on the early diagnosis and treatment of breast cancer have not yet been achieved and therefore, it is recognized that even among young people, knowledge about breast cancer is inadequate [9] and the inadequacy of knowledge and practice make early diagnosis and effective treatment difficult. An important role is played by the patients in screening participation by knowing the symptoms of the illness, accepting the dangers of the illness, understanding that they could become sick, being treated (in the event of illness) according to the screening results, and believing that the results is evaluated in a meaningful [10]. It is observed that breast cancer death rates increase by $0.4 \%$ per year in the United State between 1975 and 1989 but decrease by $39 \%$ between 1989 and 2015 averting 322,600 deaths [11]. Lack of participation in breast cancer screening measures may result into late detection. There has been considerable research to ascertain whether this is the case. The high prevalence of breast cancer highlights the need for early detection. In fact, timely diagnosis can promote the available treatment options for affected women and thereby improve the survival rate [12]. Survival in cases with tumors less than $5 \mathrm{~cm}$ in size has been reported to be above $98 \%$; as a result, researchers have focused on the early detection of breast cancer [13].

\section{Method}

A cross-sectional descriptive study design was employed in this study. This study was conducted in a selected Community in Abuja, Federal Capital Territory of Nigeria; the community was Lugbe which is located in the Kabusa ward within the Abuja Municipal Area Council (AMAC) on the eastern wing of the Federal Capital Territory (FCT). It is situated between latitudes $08055^{\prime} \mathrm{N}$ to $09000^{\prime} \mathrm{N}$ of the Equator and longitudes $07019^{\prime} \mathrm{E}$ to $07026^{\prime} \mathrm{E}$. In order to have a representative sample of the study population, in this study, a total of 317 participants (from the weekly community youth meeting) all participated in the study. Simple random sampling method was adopted.

The tools used to collect data from the respondents was Structured-self-administered questionnaires which was evaluated by two public health professionals/researchers and their inputs was incorporated into the final version of the questionnaire. The questionnaire was subjected to a pilot study involving at least 20 participants to validate the data collection tool. Also, the questionnaire comprises four sections A, B, C and D for social demographic data, knowledge of breast cancer and prevention, Attitude towards breast cancer and practice towards breast cancer respectively.

Data collected was analysis using statistical package for social scientists (SPSS version 21) tool for data analysis and Microsoft excel. This was used because they are user friendly. Results were presented using descriptive statistics of tables, pie and bar charts, and Chi-square was used to test the association between various socio-demographic variables and knowledge, attitude and practice of the female youths towards breast cancer screening. All result was set at 0.05 level of significance.

\section{Result}

Three hundred and seventeen of female youths were interviewed. About half 158 (49.8\%) were between the age 21-25 years, $118(37.2 \%)$ were between 26-30 years while $41(12.9 \%)$ were between $15-20$ years of age. About three quarter $241(76 \%)$ of the respondents were single while about one-quarter $76(24 \%)$ were married. $279(88 \%)$ of the respondents were in tertiary institutions, while only 38 $(12 \%)$ were in secondary school level. About 6 in $10-190$ $(59.9 \%)$ were practicing Christianity religion, while 127 (40.1\%) practice Islam. $183(57.7 \%)$ of the female youth respondents were students, $91(28.7 \%)$ were civil servant or professional worker, while $43(13.6 \%)$ were self-employed or a trader. 
Table 1. Socio-demographic characteristics of respondents.

\begin{tabular}{lll}
\hline Socio-demographics characteristics & Frequency & Percentage \\
\hline Age-group & & \\
$15-20$ & 41 & $12.9 \%$ \\
$21-25$ & 158 & $49.8 \%$ \\
$26-30$ & 118 & $37.2 \%$ \\
Marital Status & & \\
Single & 241 & $76.0 \%$ \\
Married & 76 & $24.0 \%$ \\
Highest Educational Qualification & & \\
Secondary & 38 & $12.0 \%$ \\
Tertiary & 279 & $88.0 \%$ \\
Religion & & \\
Christianity & 190 & $59.9 \%$ \\
Islam & 127 & $40.1 \%$ \\
Occupation & & \\
Student & 183 & $57.7 \%$ \\
Civil Servant/Professional & 91 & $28.7 \%$ \\
Self Employed/Trader & 43 & $13.6 \%$ \\
Total & 317 & $100.0 \%$ \\
\hline
\end{tabular}

Knowledge of Female Youths Towards Breast Cancer Screening

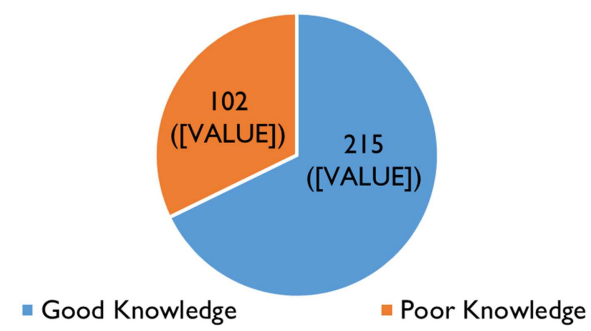

Figure 1. Pie chart showing the percentage distribution of good and poor knowledge of female youths towards breast cancer screening. The pie chart above shows that $67.8 \%$ (215) of the respondents have good knowledge towards breast cancer screening while $32.2 \%$ (102) have poor knowledge about breast cancer screening.
Attitudes of Female Youths Towards Breast Cancer Screening

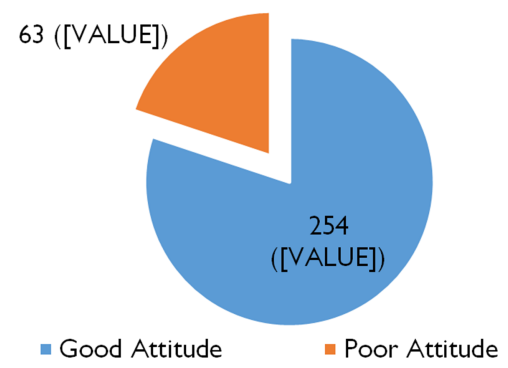

Figure 2. Pie chart showing the percentage distribution of good and poor attitude of female youths towards breast cancer screening. The pie chart above shows that $80.1 \%$ (254) of the respondents have good attitudes towards breast cancer screening while 19.9\% (63) have poor attitudes towards breast cancer screening.

Practice of Female Youths Towards Breast Cancer Screening

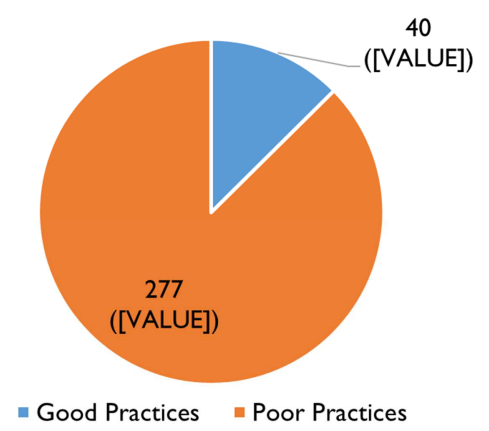

Figure 3. Pie chart showing the percentage distribution of good and poor practices of female youths towards breast cancer screening. The pie chart above shows that only $12.6 \%$ (254) of the respondents have good practices towards breast cancer screening while majority $87.4 \%$ (277) have poor practices towards breast cancer screening.

Table 2. Chi-Square analysis showing association between Knowledge of Female Youth towards Breast Cancer Screening and socio-demographic characteristics of the respondents.

\begin{tabular}{|c|c|c|c|c|c|c|c|}
\hline & Mean & Standard Deviation & Range & Minimum & Maximum & Cronbach's Alpha & No. of Items \\
\hline Knowledge Score & 1.349 & 0.164 & 0.350 & 1.177 & 1.527 & 0.814 & 5 \\
\hline \multirow{2}{*}{\multicolumn{2}{|c|}{ Variables }} & & \multicolumn{3}{|c|}{ Knowledge of Breast Cancer Screening } & \multirow{2}{*}{ Chi-square } & \multirow{2}{*}{ P-Value } \\
\hline & & & Goo & (\%) & Poorn (\%) & & \\
\hline \multicolumn{8}{|c|}{ Age-group (in years) } \\
\hline $15-20$ & & & $22(5$ & & $19(46.3)$ & \multirow{3}{*}{4.485} & \multirow{3}{*}{0.106} \\
\hline $21-25$ & & & 112 & & $46(29.1)$ & & \\
\hline $26-30$ & & & $81(6$ & & $37(31.4)$ & & \\
\hline \multicolumn{8}{|l|}{ Marital Status } \\
\hline Single & & & 180 & & $61(25.3)$ & \multirow{2}{*}{21.711} & \multirow{2}{*}{$<0.0001^{*}$} \\
\hline Married & & & $35(4$ & & $41(53.9 \%)$ & & \\
\hline \multicolumn{8}{|c|}{ Highest Educational Level } \\
\hline Secondary & & & $11(2$ & & $27(71.1)$ & \multirow{3}{*}{29.901} & \multirow{3}{*}{$<0.0001^{*}$} \\
\hline Tertiary & & & 204 & & $75(26.9)$ & & \\
\hline \multicolumn{6}{|l|}{ Religion } & & \\
\hline Christianity & & & 131 & & $59(31.1)$ & \multirow{3}{*}{0.275} & \multirow{2}{*}{0.600} \\
\hline Islam & & & 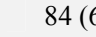 & & $43(33.9)$ & & \\
\hline \multicolumn{7}{|l|}{ Occupation } & \\
\hline Student & & & 129 & & $54(29.5)$ & \multirow{3}{*}{26.313} & \multirow{3}{*}{$<0.0001^{*}$} \\
\hline Civil Servant/Profe & & & $71(7$ & & $20(22.0)$ & & \\
\hline Self Employed/Tra & & & $15(3$ & & $28(65.1)$ & & \\
\hline
\end{tabular}

*Significant at $5 \%$ level 
Table 2 shows that more than two-thirds of respondents in the age-group $21-25(112,70.9 \%)$ and $26-30(81,68.6 \%)$ have good knowledge of breast cancer screening while about half $(22,53.7 \%)$ of respondents in the age-group 15-20 have good knowledge of breast cancer screening. About two-thirds of Christian and Muslim female students (131-68.9\%, and $84-66.1 \%$ respectively) have good knowledge of breast cancer screening. There is no statistical association between age-group, religion and knowledge about the breast cancer screening among the female youths $(\mathrm{p}>0.05)$.

There exists a significant higher proportion of singles (180, $74.7 \%)$ than married $(35,46.1 \%)$ who have good knowledge about breast cancer screening. Higher proportion of female youths in tertiary education $(204,73.1 \%)$ have good knowledge of breast cancer screening than secondary female youths $(11,28.9 \%)$. More than 7 in 10 of students (129, $70.5 \%)$ and civil servant/professional $(71,78.0 \%)$ have good knowledge of breast cancer screening while only 15 (34.9\%) of self-employed/trader have good knowledge of breast cancer screening. There is a statistically significant association between marital status, highest educational level, occupation of female youths and knowledge about breast cancer screening $(\mathrm{p}<0.05)$.

Table 3. Chi-Square analysis showing association between Attitudes of Female Youths towards Breast Cancer Screening and socio-demographic characteristics of the respondents.

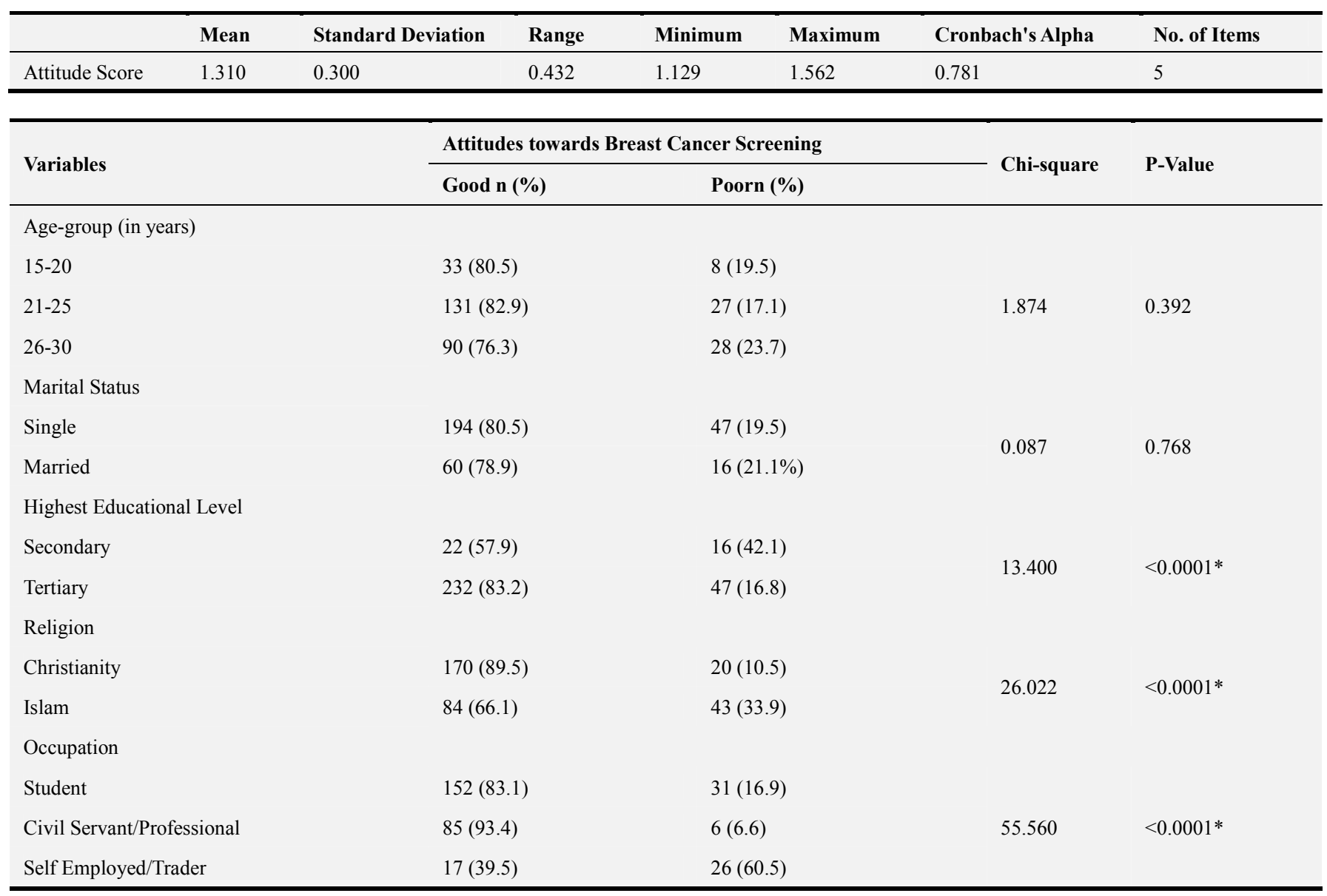

*Significant at $5 \%$ level

Table 3 shows that about 8 in 10 of all the age-groups of the female youths interviewed have good attitudes towards breast cancer screening [33 (80.5\%), $131(82.9 \%)$, and 90 (76.3\%) for 15-20, 21-25 and 26-30 age-groups respectively]. $194(80.5 \%)$ of singles and $60(78.9 \%)$ of married female youths have good attitudes towards breast cancer screening. Age-group, marital status have no statistical association with attitudes towards breast cancer screening $(\mathrm{P}>0.05)$.

More tertiary female youths $232(83.2 \%)$ than secondary
22 (57.9) have good attitudes towards breast cancer screening. More Christian female youths 170 (89.5\%) than Muslim 84 $(66.1 \%)$ have good attitudes towards breast cancer screening. Students and civil servant/professionals $(152,83.1 \%$ and 85 , 93.4\% respectively) have good attitudes towards breast cancer screening than the self-employed/trader (17, 39.5\%). Highest educational level, religion, occupation have statistical association with the attitudes of female youths towards breast cancer screening $(\mathrm{P}<0.05)$. 
Table 4. Chi-Square analysis showing association between Practices of Female Youths towards Breast Cancer Screening and socio-demographic characteristics of the respondents.

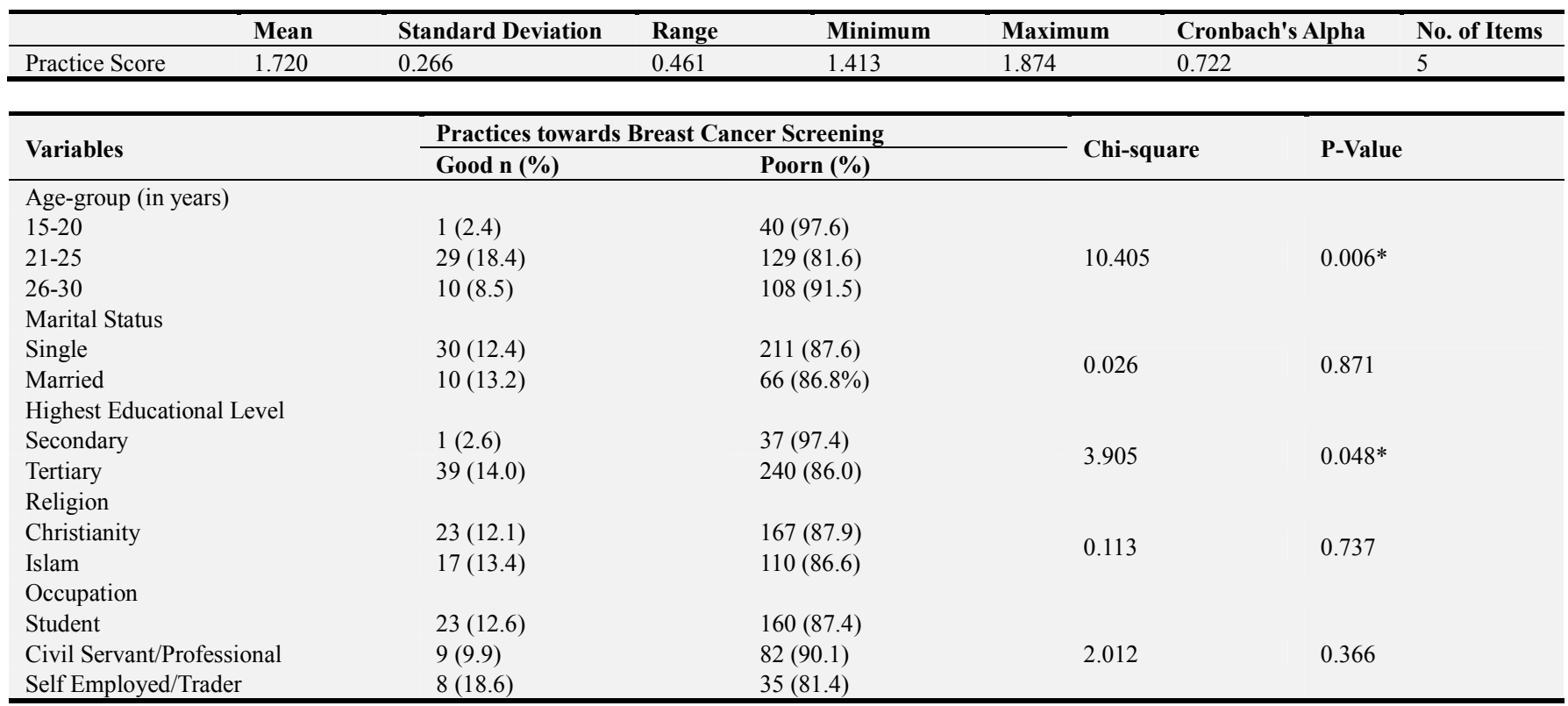

Table 4 shows that $29(18.4 \%)$ of $21-25$ female youths have good practices towards breast cancer screening followed by age-group 26-30 (10, 8.5\%) and 15-20 (1, 2.4\%). Higher proportion of tertiary female youths $(39,14.0 \%)$ have good practices towards breast cancer screening than secondary female youths $(1,2.6 \%)$. Age-group, highest educational level have statistical association with practices towards breast cancer screening $(\mathrm{P}<0.05)$.

$30(12.4 \%)$ and $10(13.2 \%)$ of singles and married female youths respectively have good practices towards breast cancer screening. More Muslim female youths (17, 13.4\%) have good practices towards breast cancer screening that the Christian female youths $(23,12.1 \%)$. Higher proportion $(8,18.6 \%)$ of self-employed/trader have good practices towards breast cancer screening than student female youths $(23,12.6 \%)$ while the civil servant/professional have the least proportion that practice good breast cancer screening $(9,9.9 \%)$. Marital status, religion, occupation have no statistical association with practices towards breast cancer screening $(\mathrm{P}>0.05)$.

\section{Discussion}

About two-thirds (67.8\%) of the female youths interviewed in Lugbe community in Abuja, Nigeria have good knowledge about breast cancer screening. Majority $(80.1 \%)$ have good attitudes towards breast cancer screening while only $12.6 \%$ do involve in good practices towards breast cancer screening. Tertiary female youths have a significant higher knowledge, attitudes and practices (KAP) towards breast cancer screening than the secondary school female youths $(\mathrm{P}<0.05)$. Students and Civil servant/professionals have a significant higher Knowledge and Attitudes towards breast cancer screening than the self-employed/trader $(\mathrm{P}<0.05)$. Singles female youths have higher knowledge about breast cancer screening than the married $(\mathrm{P}<0.05)$.
More Christian female youths than the Muslim have good attitudes to breast cancer screening $(\mathrm{P}<0.05)$. Age-group 2125 of female youths have the highest level of good practices towards breast cancer practices, followed by 26-30 age-group $(\mathrm{P}<0.05)$.

Increasing cancer screening rates among female youth populations is vital because early detection is intermediate to reducing morbidity and mortality due to breast cancer. The prevalence of breast cancer among young women is extremely low and young age is a bad prognostic factor for the treatment of breast cancer [14, 15]. In a study, it is revealed that young age is the second most powerful risk factor among premenopausal women after lymph node status [16]. Therefore, early detection is important in this age group [14]. With regard to the level of individual's knowledge about breast cancer, appreciable proportion of the study subjects were found with good knowledge (34.3\%), but for females, $28.2 \%$ and $15.8 \%$, were found with moderate and poor knowledge, respectively Alharbi, et al. [18]. This is also in accordance with this research where more than two-thirds of respondents in the age-group 21-25 (112, 70.9\%) and 26$30(81,68.6 \%)$ have good knowledge of breast cancer screening while about half $(22,53.7 \%)$ of respondents in the age-group 15-20 have good knowledge of breast cancer screening. There is no statistical association between agegroup, religion and knowledge and the breast cancer screening among the female youths $(p>0.05)$. There exists a significant higher proportion of singles $(180,74.7 \%)$ than married $(35,46.1 \%)$ who have good knowledge about breast cancer screening. Higher proportion of female youths in tertiary education $(204,73.1 \%)$ have good knowledge of breast cancer screening than secondary female youths (11, $28.9 \%)$. More than 7 in 10 of students $(129,70.5 \%)$ and civil servant/professional $(71,78.0 \%)$ have good knowledge of breast cancer screening while only 15 (34.9\%) of self- 
employed/trader have good knowledge of breast cancer screening. There is a statistically significant association between marital status, highest educational level, occupation of female youths and knowledge about breast cancer screening $(p<0.05)$. This study result is at variance with the finding of a study by Majed Alshahrani et al. [19] which showed a low-level knowledge of breast cancer in general, mammogram, clinical breast examination, and breast selfexamination in female.

The findings in this study can also be compared to a study in India which showed more than half of women were aware of breast cancer [20]. Another study in china is also in agreement with the present study which showed that close to three quarter $(71.8 \%)$ of female participants has good Knowledge regarding breast cancer while $28.2 \%$ were unmindful [21]. This study is also in contrast with other findings which reported poor knowledge of breast cancer and the screening methods. A study from Jordan contradict this study which show that a lot of Jordanian women had scaring poor levels of knowledge of breast cancer [22]. knowledge of breast cancer was low among 411 Jordanian woman aged 1870 years in Amman, the capital of Jordan [23].

On attitude, this study shows that about 8 in 10 of all the age-groups of the female youths interviewed have good attitudes towards breast cancer screening (80.5\%), 131 $(82.9 \%)$, and $90(76.3 \%)$ for $15-20,21-25$ and 26-30 agegroups respectively. $194(80.5 \%)$ of singles and 60 (78.9\%) of married female youths have good attitudes towards breast cancer screening. Age-group and marital status have no statistical association with attitudes towards breast cancer screening $(\mathrm{P}>0.05)$. This study finding also agreed with a study by where about $78.4 \%$ of the respondents shows good attitude towards breast cancer screening [24]. A study conducted in Pakistan is also in agreement with this study result in which Majority $(246,80.9 \%)$ of his participants shows positive attitude but poor knowledge which could have influence their poor practice too [25]. This study also shows that more tertiary female youths $232(83.2 \%)$ than secondary 22 (57.9) have good attitudes towards breast cancer screening. More Christian female youths 170 (89.5\%) than Muslim 84 $(66.1 \%)$ have good attitudes towards breast cancer screening. Students and civil servant/professionals (152, 83.1\% and 85, 93.4\% respectively) have good attitudes towards breast cancer screening than the self-employed/trader $(17,39.5 \%)$. Highest educational level, religion and occupation have statistical significant association with the attitudes of female youths towards breast cancer screening $(\mathrm{P}<0.05)$. A supportive study by Grace et al., 2016 shows that 95 (67.9\%) had positive attitude towards breast cancer screening while $45(32.1 \%)$ had negative attitude towards breast cancer screening.

Considering the practice towards breast cancer, this study showed majority of the youth do not practice breast cancer screening which may be due to inadequate screening facility and poor awareness on the importance of breast screening. Few participants 29 (18.4\%) of 21-25 female youths have good practices towards breast cancer screening followed by age-group 26-30 (10, 8.5\%) and 15-20 (1, 2.4\%). Higher proportion of tertiary female youths $(39,14.0 \%)$ have good practices towards breast cancer screening than secondary female youths $(1,2.6 \%)$. Age-group and highest educational level have statistical association with practices towards breast cancer screening $(\mathrm{P}<0.05) .30(12.4 \%)$ and $10(13.2 \%)$ of singles and married female youths respectively have good practices towards breast cancer screening. More Muslim female youths $(17,13.4 \%)$ have good practices towards breast cancer screening that the Christian female youths (23, $12.1 \%)$. Higher proportion $(8,18.6 \%)$ of selfemployed/trader have good practices towards breast cancer screening than student female youths $(23,12.6 \%)$ while the civil servant/professional have the least proportion that practice good breast cancer screening (9, 9.9\%). Marital status, religion and occupation have no statistical significant association with practices towards breast cancer screening $(\mathrm{P}>$ 0.05). Study also shows that more than half of his participants had poor practice, having not been practicing any of the three preventive measures [24]. A study in Pakistan also show that majority of participants has poor practice which may possibly be attributed to poor knowledge.

From this study research, it is evident that majority has a good knowledge and attitude about breast cancer with poor practice to breast cancer screening. Poor practice can be attributed to inadequate accessibility to source of information about the importance and advantage of early breast cancer screening, religion, culture and belief. However, poor practice can not only be attributed to inadequate knowledge about how and when to do the breast cancer screening as other factors such as lack of screening center, poor knowledge on how to do breast self-examination among others can be a contributing factors.

\section{Conclusion}

In conclusion, this research has shown that majority of female youth has good knowledge and attitude about breast cancer screening but has poor practice towards breast cancer screening which is in tandem with the research conducted [17]. It was also discovered that married female youth and traders have poor practice but good knowledge towards breast cancer screening. Higher proportion of selfemployed/trader have good practices towards breast cancer screening than student female youths while the civil servant/professional have the least proportion that practice good breast cancer screening. Marital status, religion, occupation have no statistical association with practices towards breast cancer screening $(\mathrm{P}>0.05)$. Generally, this finding shows that presence of good knowledge and positive attitude towards breast cancer screening should not be assumed for willingness to practice preventive strategies.

\section{Recommendation}

With reference to the findings of this study, it is highly recommended that schools, community, religion centres and 
government should design programs that will create better awareness on the importance of breast cancer screening, how it is done, when and where breast cancer screening can be accessed. It is also indispensably important that screening facilities should be provided in primary health care centres to improve availability and accessibility to this essential lifesaving service among young female population.

\section{References}

[1] Garcia $M$ et al. Global Cancer Facts \& Figures. Atlanta, GA: American Cancer Society, 2007.

[2] WHO Cancer factsheet $\mathrm{N}^{\circ} 297$ updated February 2009. Last accessed April 2011 at http://www.who.int/mediacentre/factsheets/fs297/en/index.ht $\mathrm{ml}$

[3] Globocan (IARC). Estimated breast cancer incidence and mortality in Ethiopia. International agency for research on cancer. 2012. $25 \mathrm{p}$.

[4] Siegel RL, Miller KD, Jemal A. Cancer Statistics, 2019. CA Cancer J Clin. 2019; 69: 7-34.

[5] Siegel RL, Jemal A, Wender RC, Gansler T, Ma J, Brawley OW. An assessment of progress in cancer control. CA Cancer J Clin. 2018.

[6] American Cancer Society, National cancer database (5 Year BC prognosis) (2009-2010). Last accessed April 2011 at http://www.cancer.org/Cancer/BreastCancer/OverviewGuide/b reast-cancer-overviewsurvival- Rates

[7] Ferlay J, Ervik M. Cancer incidence and mortality worldwide. IARC Cancer Base 2012. 1: 1-5.

[8] Warner E, Plewes DB, Hill KA, Causer PA, Zubovits JT, Jong RA, et al. Surveillance of BRCA1 and BRCA2 mutation carriers with magnetic resonance imaging, ultrasound, mammography, and clinical breast examination. Jama, (2014); 292 (11): $1317 \pm 1325$.

[9] Karayurt O, Ozmen D, Cetinkaya AC. Awareness of breast cancer risk factors and practice of breast self examination among high school students in Turkey. BMC Public Health. 2008; 8: 359. https://doi.org/10.1186/1471-2458-8-359 PMID: 18928520

[10] Tezcan S. Epidemiyoloji Tõbbi Araştõrmalarõn YoÈntem Bilimi [Turkish]. Ankara: Hacettepe Halk SağlõğõVakfõ; (1992).

[11] DSantis CE, Ma J, Sauer AG, Newman LA, Jemal A. Breast cancer statistics, 2017, racial disparity in mortality by state. CA Cancer J Clin 2017; 67: 439-448. (PMID: 28972651) [CrossRef].

[12] Faronbi JO, Abolade J. Breast self-examination practices among female secondary school teachers in a rural community in Oyo State, Nigeria. Open Journal of Nursing. 2012; 2 (2): 111-115.
[13] Gerling GJ, Weissman AM, Thomas GW, Dove EL. Effectiveness of a dynamic breast examination training model to improve clinical breast examination (CBE) skills. Cancer Detection and Prevention. 2003; 27 (6): 451-456.

[14] ShMamoon, Smith IE (2003). Breast cancer in adolescents and young women. Eur J Cancer, 39, 2632-42.

[15] Maureen Chung, Helena R. Chang, Kirby I. Bland, Harold J. Wanebo (1996), Younger women with breast carcinoma have a poorer prognosis than older women. Cancer, 77, 97-103.

[16] Peter C. Dubskya, Michael F. X. Gnanta, Susanne Tauchera, et al (2002). Young age as an independent adverse prognostic factor in premenopausal patients with breast cancer. Clinical Breast Cancer. Volume 3 (Issue 1), 65-72.

[17] Alharbi Saleh Hadi, Fayez Saud Alreshidi, Ibrahim A. Bin ahmed, Ali Ghannam Alrashidi, Sami Awejan Alrashedi, Kalaf Jaze Kalaf Alshammeri and Hussain Gadelkarim Ahmed 2 International Journal of Medical Research \& Health Sciences, 2018, 7 (1): 65-76.

[18] Majed Alshahrani, Sultan Yahya M. Alhammam, Hussain Ali Salem Al Munyif, Amani Mohammad Abbad Alwadei, Alanood Mohammad Abbad Alwadei, Soha Saleh Mohammed Alzamanan, Norah Saad M. Aljohani, Journal of Cancer Education (2019) 34: 1167-1172.

[19] Somdatta P, Baridalyne N (2008) Awareness of breast cancer in women of an urban resettlement colony. Indian J Cancer 45: 149-153.

[20] Sanjay Kumar Sah, Anupama Pradhan (Thaiba), Nira Neupane, Sabita Shah, Priya Shrestha and Anu Paudel.: Knowledge, Attitude and Practice Regarding Prevention and Screening of Breast Cancer among Reproductive Age Women 2019.

[21] Adenike and Omuemu (2009): knowledge, attitudes, and practice of breast cancer, screening among female health workers in a Nigerian urban city. Available at: www. Biomedcentral.com 4 (9) 147-203.

[22] Ahmed F, Mahmud S, Hatcher J, Khan SM. Breast cancer risk factor knowledge among nurses in teaching hospitals of Karachi, Pakistan: A cross-sectional study. BMC Nurs 2006; 5: 6.

[23] Azubuike SO, Okwuokei SO (2013). Knowledge, attitude and practices of women towards breast cancer in Benin City, Nigeria. Ann. Med. Health Sci. Res. 3 (2): 155-160.

[24] Samina Rafique, Zainab Waseem and Fatima Sheerin DOI: 10.26717/BJSTR.2018.04.001100 Samina Rafique. Biomed J Sci \& Tech Res.

[25] Zahid Ali Memon, Noureen Kanwal, Munam Sami, Parsa Azam Larik, Mohammad Zain Farooq DOI: http://dx.doi.org/10.7314/APJCP.2015.16.17.7485 Risk of Breast Cancer among Young Women and Importance of Early Screening in Pakistan. 